\title{
Questioning Normal
}

\section{Overcoming implicit resistance to norm critical education}

\author{
By Liv Moeslund Ahlgren \& Ehm Hjorth Miltersen
}

Sunlight creeps in through the blinds in the classroom window. We just finished writing our names and pronouns on the blackboard, and we now turn to face the twenty-three 7th-graders in the room. We present ourselves, briefly explain how to use our pronouns, and say that we're from an organization called Normstormerne ("The Norm Stormers"):

"Have you heard anything about what we're here to do together with you today?" we ask, and the teenagers are quiet for a few moments, either shy or hesitant. One raises a hand.

"You're here to talk about bullying."

Another adds: "We heard some gays were coming."

Indeed, Normstormerne's work deals with both bullying and gay people - but this is just a fraction of the topics we adress. Normstormerne is a norm critical and intersectional organization offering workshop-based education at schools and for adults working with children and youth. In our workshops we demonstrate how social norms create the foundation for discrimination and oppression, especially related to LGBTQIA+ identities. That's where the "bullying" and the "gays" come in. Our aim, however, is not just to talk about how LGBTQIA+ people overcome bullying. We are not here to share a personal story about what it is like to be a LGBTQIA+ person. Rather, we discuss how norms are the reason why LGBTQIA+ people - and other marginalized groups - become a minority group in the first place, and how norms affect the way this minority group gets excluded from the 'us' and the 'normal,' thus creating a platform for bullying. Moreover, Normstormerne also teaches how norms are social constructs that can be affected and changed by human beings. We do this through various exercises so the pupils get an age-appropriate, concrete and hands-on understanding of the concepts. The project has the activist purpose of enabling young people to both identify norms, but also provide specific tools for changing the norms that contribute to oppression and discrimination.

Normstormene has existed since 2012 and teaches at schools mainly in and around Aarhus and in Copenhagen, but also in other parts of the country. The pupils are often interested in our knowledge, methods, and perspectives and participate actively in the workshops, and many teachers tell us that they're excited and glad that Normstormerne exists. But sometimes we meet resistance from both pupils and teachers. Generally, this resistance takes two different forms: Explicit and implicit resistance. The explicit 
resistance comes from teachers or students who explicitly disagree with our values or methods and argue against us. This type of resistance is probably well known among activists. Just as relevant, though, is the implicit resistance that comes from those who already support feminist progression teachers who have invited us to come and enthusiastically participating pupils. In general, they want to make a positive change, but object towards making radical changes to the status quo. This implicit resistance is possibly well-meant, but ultimately reinforces existing norms and structures. In this essay, we take a look at how this plays out in the classroom, how it reflects society at large, and how we as activists tackle it all.

\section{The gay zoo}

The implicit resistance meets us at the beginning and throughout each teaching session. It starts as soon as we ask the pupils what they have heard about us and our work: It may or may not be that their teacher has told them that we're "gays" coming to "talk about bullying", but either way, the fact that the pupils have this perception reflects the norms for doing diversity and inclusivity work in schools. Often, teaching about diversity becomes more about learning to tolerate minority groups rather than questioning why they are minoritized in the first place. In tolerance-based inclusivity education, the idea is that tolerating (or even "accepting") someone is a kind and welcoming action, but in practice, it means minoritized people become people who aren't a part of an "us". The notion is created that some people are "normal" and others are not, and it is the privilege of the "normal" people to tolerate the others. The minoritized people become othered, because to tolerate someone is to acknowledge that they are not like you and, implicitly, that this gives you the power to accept or reject their existence. Tolerance is a way of reinforcing power dynamics that gives the majority the right to define who is included. The idea of tolerance is one of the major forms of implicit resistance we meet. It is well-meant, but it doesn't challenge any underlying structures.
Many teachers - kind and well-meaning teachers who want to show their pupils that everyone deserves respect - want to teach about LGBTQIA+ topics by inviting a gay or trans person into the classroom and have them talk about themself and their life. The teachers want to show the pupils an example of a gay or trans person, because, the assumption is, they won't encounter someone like that elsewhere. Introducing LGBTQIA+ identities like this - The Special Guest of the Day for this very Special Topic - just emphasizes for the LGBTQIA+ pupils in the classroom that they are indeed the Others, the odd-ones out, the exceptions. The classroom becomes a zoo where the "normal" pupils can learn about the Other and be told that they should tolerate this Other and treat them nicely. When the guest has left, everything can go back to "normal" and the pupils don't have to think about "the gays" anymore if they don't want to.

This way of thinking is not restricted to the classroom. As people with minority status are Othered, we also become more noticable simply because we are seen as "special". It's what happens when a group composed of 30 women and 70 men is seen as female-dominated. Or when portrayal of same-sex couples or transgender people in media is seen as "shoving their identities and sexualities in people's faces". When nonbinary people are accused of the same just by existing, period. Or when persons with non-Danish ethnic background cannot speak out against discrimination or comment on related topics (or, often, any topic) without being dismissed as being biased. When a niqab is seen as a barrier preventing interpersonal contact, but sunglasses and a face mask are not. When trans women are kept out of women's restrooms while risking assault in the men's, perceived as intruders in both spaces. When fat people see their doctors for an unrelated medical issue and are told to lose weight before anything else, often resulting in misor undertreatment. When fat people are scolded for eating fatty foods ("you're making it worse") or diet foods ("who do you think you're kidding?"). When transgender people are told they're too feminine or masculine, just reinforcing gender stereotypes, or not feminine or masculine enough, because then 
how can they really be trans? When any minority person expresses anger. The list goes on and on. People with minority status are perceived as taking up more space than we do, even when we barely have room to exist at all. We are seen as guests in the majority's space. We may be tolerated, but it is not our space to claim.

No one should be reduced to this. We, Normstormerne, do not want LGBTQIA+ people to be merely guests in the classroom - when we leave, we don't want our existence to leave with us. Instead of our visit being a brief respite from "normal", we want to teach the pupils that they are partaking in creating - and thus can change - normal. Instead of focusing on the Other, we want them to look at normal - and be critical of it. Why is this normal? Couldn't it just as well have been anything else? Should this be normal? Should anything be normal - is that even a positive thing to create and uphold? What can we do to change it?

The implicit resistance we meet here stems from the idea that LGBTQIA+ identities are not already present in the classroom, and that these identities should be introduced and at best tolerated. It possibly (though not necessarily) comes from a place of goodwill but ends up reinforcing the division between "us" and "them" and leads to the exclusion of LGBTQIA+ persons from the "normal". Even if the point is presented that "they (we) are (a kind of) normal, too", this upholds the idea some things are "normal" and others are not, and that Normality is good and desirable. All of this is something that Normstormerne strive to challenge and change.

\section{Spotting the norms}

The workshop is getting properly started, and all of us, both pupils and Normstormers, are sitting in a circle. We're doing an exercise where one of us reads aloud a series of statements, and the pupils are to stand up and swap seats if they agree with the statement, or stay seated if they disagree.

We're at one of the last statements of the exercise: "I'm used to seeing people who use wheelchairs in the media."
The pupils shift in their seats, some mumble to each other. They seem confused. We give them a moment before asking what that statement makes them think.

One pupil comments that there are much fewer people who use wheelchairs than people that don't, so it's silly to expect them to show up in the media. We ask if they think the kind of people usually seen on TV and in advertisements - white, thin, cis, and able-bodied - are really overwhelmingly the most common type of person. If the proportion of this kind of person seen in the media matches the proportion in the real-life population.

Often, the pupils seem convinced that the media landscape really does match reality, even as we argue that the numbers are skewed. Eventually they may admit, "Maybe not." Then they might go on: "But still. You can't put every type of person in a movie." We ask back: "Why?"

This is another type of implicit resistance we meet - the idea that some things are a certain way "just because", and that there is no reason to further explore why. The fundamental idea that Normstormerne wants to present is that "normal" is made up of power structures and norms, assumptions and expectations. For example, the lack of media representation is a direct consequence of the ideology of the people in power. Norms are powerful because they are invisible, and we all grow up in a society organized by these invisible norms. In the classroom, we discuss the fact that it can be harmful to never see someone who looks like yourself in the movies, TV shows, advertisements and other media you consume. The resistance the pupils exhibit towards this idea often comes from a lack of personal experience. We know that because individual pupils with minority status and very diverse classrooms in relation to race, religion, (dis)ability, class etc., are often much quicker to catch on. They have personal bodily experience with underrepresentation and the consequences of breaking social norms due to marginalization, and can often more easily spot why other minoritized groups experience the same.

The implicit resistance described here mirrors what takes place in society in general. Since minority groups are perceived as taking up 
excessive space, the disproportionate amount of space the majority occupy in positions of power goes unnoticed. The first step towards change is to recognize that this inequality is neither fair, nor representative of the actual population. It can be a hard point to drive home for both teenagers and adults alike. You have to start searching for things that you are used to being indiscernible.

The implicit resistance we meet here is the idea that "normal" is nothing more than just "normal". When confronted with this, we try to explicate just how norms - exactly by being invisible - control, for example, who gets represented in the media. We want to make the norms visible by questioning the "normal" and repeatedly responding by asking: "Why?"

\section{Can the norms be changed - and should they?}

We are about halfway through the workshop. The sunlit window has been opened to let in some fresh air to fuel our brains after almost an hour of thinking, discussing, and getting used to new ideas. The pupils have been hard at work, but after a short break we are ready to move on to the next exercise. We present a short case story and ask the class to discuss how the different characters in the story might act in order to improve the situation. The stories revolve around a specific instance of oppression, discrimination, or microaggression: A new player on the football team experiences his coach yelling homophobic slurs as encouragement; a pupil is kicked out of either gendered bathrooms because of their appearance; a class throws a party but the venue is on the 3rd floor with no elevator, barring a pupil using a wheelchair from attending.

"She should just pick one or the other bathroom," a pupil exclaims, "or go at home. Stop being a bother."

"If there's nowhere else to throw the party, that kid will just have to not come. Too bad. They can attend the next party", another argues.

Explicit resistance like this pops up regularly in our classroom discussions. Some people are just going to have a harder time than others, the argument goes, and if they want to improve their conditions, they'll have to work to achieve it on their own. The gay kid on the football team needs to "man up"; the trans or gender nonconforming kid has to keep their head down; the kid using a wheelchair will have to do the work of throwing their own party at an accessible venue. The majority of the pupils won't necessarily outright exclude them if these kids manage to claw their way into a normative-esque state - but they won't do anything to help, either. Equality is too much work to be worth striving after; not everyone can be accommodated.

Luckily, it's not always like this. Lots of pupils are kind and sympathetic. But despite the support, we still meet the idea that some things just cannot be changed, and that individuals are responsible for solving their own problems. This is yet another form of implicit resistance we are met with.

"The teachers have their own bathroom," someone says, "so the pupil can be allowed to use that one."

"Do you think it might feel a little lonely or even embarrassing to be the only one who has to use an entirely different bathroom from everyone else?" we ask.

“Well, if he or she doesn't like it, there aren't many options left."

Where the resistance in the earlier exercise came from being unable to see the ruling norms, the resistance here is due to not seeing how or why those norms should be changed. The pupils may acknowledge that gender norms are present and that they make life difficult for some people - but more often than not, they don't draw the conclusion that the best solution is to actually change these problematic norms.

"That's just the way things are", they say.

People are generally used to being told "how things are", so their line of reasoning might stop there. If they do try to rationalize it, they might appeal to biology or evolutionary theory to explain discriminatory structures, or they'll argue that the world is what it is, and it's up to the individual to overcome their difficulties through hard work. When you have lived in a world that seems 
to be a certain way for your whole life, especially if that world treats you quite well, it can be more appealing to explain why it's naturally like that rather than acknowledge that it's a product of continued reproduction of norms and in fact could be different. If the world "just is" a certain way, each person is only responsible for their own happiness, or perhaps for that of the ones closest to them. But because we are all continuously responsible for maintaining harmful norms and structures, then we all have a duty to change and create change.

The pupils usually agree with the fundamental humanist ideology that everybody is worth something and should be treated as equals. But what they are resistant towards is the possibility of changing the structures instead of changing the behavior of individuals. Our job at this point is to present the idea that norms can be changed. We can make all the bathrooms gender neutral, we can accommodate everyone's dietary needs and preferences, we can make an agreement that all parties are held at accessible venues. When the pupils accept this idea - that it is possible to make up new agreements, new norms - they can reach a solution to the case story we brought them. If they are quick, we might push them a little - variants of the case stories are harder because the norms in them are even more integrated and harder to imagine changing. A case about gendered changing rooms rather than gendered bathrooms is met with more resistance, for instance. Both norms are rooted in the idea that facilities that involve some degree of undressing requires gender segregation, and both can be rebutted by references to places where this isn't the case (bathrooms in private homes and many workplaces are rarely gender specific, and unisex shared changing rooms do exist e.g. in many Danish winter swimming facilities) and by arguing that differentiating between bodies of different genders is neither as straightforward or crucial as it may seem. But most people still more readily accept unisex bathrooms than unisex changing rooms. The norm that different genders must hide their naked bodies from each other is stronger than the norm that those bodies must tend to their needs in separate bathrooms. But while the norms are of different strengths, both serve to marginalize transgender, nonbinary, and gender-nonconforming persons.

The key is the idea that norms and structures, not individuals, are responsible for much of the hardship that minority groups (and in many cases majority groups, too) experience. It is not enough to convince single prejudiced individuals not to bully minority people. The structures of society need to change. It's an abstract idea that can be hard to grasp. But it can help to be provided with some specific tools and strategies for changing the harmful norms.

\section{How to change the norms}

For the last exercise, the pupils are working in groups to find a solution to the case stories we gave them. We have assigned different roles to the groups. One group has to figure out what the person from the case story can do about their situation. Another group plays the role of the classmates, yet another take on the role of the parents or other adults, and one group is the teacher and the school board. The last group is society at large - politicians, the media and the general public.

"The pupil can ask the school to install gender neutral bathrooms" the first group says after discussing the case story about the pupil getting kicked out of the bathrooms.

"But what if the pupil is embarrassed? Or if the school doesn't care?" we ask.

"Well, then there is not much you can do."

It can be tempting to give up once the established system and norms stand in the way of a proposed solution. But in another case story these suggestions comes up:

"The classmates can go together and demand that the party should be held in an accessible venue," says the group that portrays the classmates.

"Right," we say, "That would solve the problem for now. But what about next time?"

They ponder for a moment.

"Oh! Then we can make a rule about it." 
"And what would the consequences be in the future?"

"Then we would get used to it. We would learn that many people use wheelchairs and of course it should be able to fit in the room."

Two important things happen when we do this exercise with the pupils. First of all, it becomes clear that one individual facing a problem cannot necessarily solve it alone. However, with the combined effort of the whole class, very much can be changed. It is easier to demand fair treatment of yourself and others through cooperation and solidarity, empowering each other's voices. Secondly, the pupils start figuring out solutions that could prevent the problem from arising in the first place and thereby actually changing the norms. They start to realize that it's not enough to just solve the problem once. They also figure out, and this is perhaps more important, that it is actually not that difficult to prevent the problem from occurring at all. Making a rule about wheelchair accessibility for school events or a policy about not using homophobic language is straightforward enough for teenagers to tackle and this rule directly challenges the problematic "normal" and thereby works to change the norms.

The solutions that the pupils come up with recognize how discrimination is based on invisible norms and that discrimination therefore has to be fought against by changing these very structures. Moreover, they are solutions that the pupils believe are possible. They have realized that norms can be changed by human beings - including themselves.

It sounds so easy when the pupils say it like that at the end of our workshop, but this realization means the pupils have come a long way. We don't always reach this state with each class, either - sometimes we make do with planting a seed and hoping the pupils will get the full idea some time down the road. If you have lived the first thirteen-to-fifteen years of your life thinking that the world has one, natural state that everyone has to accept, one ninety-minute workshop won't necessarily turn that upside down. But we can present the idea that we, as human beings, define the norms, and that Normality isn't necessarily a perfect ideal worth striving for. We can then hope that the pupils will want to make the spaces they are part of, including society as such, as accountable, inclusive, and caring as possible.

\section{Changing the world one classroom at a time}

In many ways, implicit resistance is as hard to tackle as its more explicit counterpart. Direct sexism, racism, homophobia, transphobia, and ableism are not easy to counter, but at least the enemy is right there in front of you in the form of hateful convictions or oppressive legislation. But when we meet implicit resistance from people who already believe they are equal and fair, we have to change larger structures and worldviews. We need to go from "tolerating and accepting the Other" to "questioning the Normal". Counter-intuitively, we need to have a conversation with those who claim they're already on our side about the fact that in reality they're not - and what they have to change to actually get on our side.

This happens in the classroom and in society at large. The methods for change are the same: dialogue, reflection, critical analysis, solidarity, and striving for social justice. Most importantly, an insistence that there's no "natural order of things" and that norms creating platforms for discrimination can and should change. An insistence that we can make that change. In Normstormerne, we are convinced change starts small and early. Children and youth should grow up with the conviction that they are capable agents in the world we live in. That they all deserve fair treatment and equal rights, and that they can and should work and contribute to ensure that. That they should always ask questions when they're told "that's just how things are" and when they meet injustice - no matter whether that injustice is explicit hate or implicit, biased norms leading to hate. By teaching children and youth to question harmful norms, we can contribute to creating a world of human beings who will fight all levels of injustice when they encounter it. 